\title{
The effect of using concrete-filled tube columns on steel moment frame with different numbers of stories by dynamic time history analysis
}

\author{
Farshad Shekari ${ }^{1}$, Mohsen Oghabi ${ }^{2 *}$ \\ ${ }^{1-D e p a r t m e n t ~ o f ~ C i v i l ~ E n g i n e e r i n g, ~ C o l l e g e ~ o f ~ E n g i n e e r i n g, ~}$ \\ Kermanshah Branch, Islamic Azad University, Kermanshah, Iran \\ 2-Department of Civil Engineering, College of Engineering, \\ Kermanshah Branch, Islamic Azad University, Kermanshah, Iran
}

\begin{abstract}
This study was carried out aimed to investigate the effect of using concrete-filled steel tube (CFT) columns on steel moment frame with different numbers of stories by dynamic time history analysis. FEM method (formerly ABAQUS) was used for modeling. A model was first modeled in Abacus software according to the conditions and dimensions of the laboratory model and subjected to lateral cyclic loading. According to the results of comparison of hysteresis behavior, the specimen with CFT column has higher residual behavior and energy dissipation than the simple steel moment frame. Frame with CFT column has higher energy dissipation and lower resistance drop. 24 numerical models with 1,2 and 3 stories were analyzed under different earthquakes. Time history charts of different models were compared. According to the results, the use of steel filled with concrete leads to increase the load-bearing of the frame in steel frame. Filling the steel column with concrete prevents the buckling of the concrete into the column and delays the local buckling of the steel wall. Concrete-filled steel frame steel has a better energy dissipation behavior than steel frame. Roof displacement of different frames with CFT column was lowers than that the roof displacement of steel frame, which indicates the frame performance has improved. The presence of concrete in the column has a significant effect on the behavior of the frame so that damage in the CFT column occurs at the panel zone where the column generally has a good behavior, but occurs in the steel column under buckling earthquake in the column.
\end{abstract}

Keywords: Bearing capacity, Cyclic Loading, Local buckling, Panel zone.

\section{Introduction}

Steel and concrete are used extremely widely as building materials in almost all structures. Although steel has many advantages in building, it has disadvantages such as decreased resistance against heat, rust and corrosion, global buckling and local buckling. There are usually problems in the construction of steel structures, such as high cost, vibration, local buckling and bearing, and in many cases the air voids inside of steel beams and columns is not used, which these spaces themselves can be used as a free mold. Some of the most important disadvantages of reinforced concrete columns and beams include the cost of molding and wasting time in construction. Also the ratio of resistance of reinforced concrete beam or column to its dimensions is low. Designers and builders venture on using these materials simultaneously due to the disadvantages of steel and concrete. It is common to use composite columns instead of conventional steel and concrete columns. Concrete-filled tube (CFT) columns are used in structures with different heights and land-use, and are widely used as columns and beam-column in structures. The use of CFT columns leads to improve structural properties against seismic stresses and provide uniform seismic resistance in two directions perpendicular to each other. It can be said that the idea of Concretefilled tube (CFT) columns has been raised to fix the disadvantages of reinforced concrete and steel structures. Concrete-filled tube (CFST) columns are used in different structures in both seismic and non-seismic areas and are widely used as columns and beam-column in structures. CFT columns can improve structural properties in the face of earthquakes and can provide uniform seismic resistance in two directions perpendicular to each other. Its components behave as composite, it means that the concrete and steel elements act in a composite manner. The concrete core in the composite column not only leads to only counteracts compressive forces but also reduces the buckling potential of the steel members. Lighter steel sections are needed due to the importance of optimum use of steel in tall buildings and the use of concrete compressive strength in columns. Also, the concrete strength is greatly increased due to the confinement and the local buckling of the steel is prevented, so it can be concluded that there is a need for further investigation to judge on the behavior of CFT columns. 


\section{Background research}

Patel and Thakkar (2013) during a study analyzed CFT columns in concrete structures. According to their results, in the CFT column, they received less attention compared to the coated column. They investigated the 10, 20, and 30 storey structures of filled-concrete tube (CFT), R.C.C and compared the parameters such as duration, displacement, base shear and carrying capacity load with steel structures and R.C.C is performed. According to the results, the CFT structure is well in load capacity with a small cross-sectional area of the carrier column [1]. Tailor et al. (2017) conducted a study aimed to evaluate the comparative performance of building steel columns and concrete-filled tube columns under static and dynamic loads. They replaced and investigated the columns of steel building were replaced with concrete-filled tube columns with two circular and square sections. Then, they compared seismic performance of both frames. They concluded that the seismic performance of concrete-filled steel pipe (CFST) of the column frame was better than steel frames in both static and dynamic loading and it's also proven to be more affordable than steel frame [2].

Jamaluddin et al (2013), conducted an in vitro study on a concrete-filled elliptical column under axial pressure. The concrete-filled elliptical column was used to determine the effect of component's geometry and constituent properties on the behavior of structure. For example, there are no design guidelines currently available in any code of exercise, the present study investigates the current design rules for concrete-filled circular hollow section columns in 4 Eurocodes. New equations were proposed according to Eurocode- 4 rules for concrete-filled circular hollow section columns and used to predict elliptical CFT column capacity [3].

El-Heweity (2012) conducted a study aimed to investigate the performance of concrete-filled circular hollow section columns under axial load. They evaluated the column performance at the axial load of the carrying capacity and the enhancement of both strength and flexibility with respect to concrete enclosure. They investigated two parameters of the increased strength coefficient and the ductility coefficient. According to the results, both parameters of concrete strength and CFT column flexibility were increased. Increased stress of steel tubes has very little effect on concrete strength and ductility [4]. M.H. Lai, J.C.M. Ho, (2013), during a study investigated a uniaxial compression test of steel enclosed steel tubes columns with rods and According to their results: CFST columns was adopted by composite operation due to their excellent performance and flexibility. However, this useful composite operation cannot be fully developed in the early elastic phase as the steel dilates more than the concrete and thus causes a defective interface connection. Therefore, it reduces the elastic strength and stiffness of the CFST column. In order to solve the problem, the lock is in the shape of a tie rod is suggested in the present study to limit the lateral dilation of concrete and steel in the elastic phase. This study tested various CFST columns in different sizes with different concrete strength and installing tie rod under uniaxial pressure. And reduction in the amount of power degradation from the CFST column (1) of the neck can lead to increase the axial load capacity (on average, 5\% up to 16\%): it was clear according to the results. (2) The neck didn't have a significant effect on improving the elastic stiffness of the CFST column. (3) The neck had a significant effect on restraining the lateral deformation of core concrete and steel tubes in site of the tie cap. But, the confined pressure between the tie caps has decreased on both the horizontal and vertical planes [5]. Gunasekaran et al. (2013) during an in vitro study investigated CFT column under cyclic steel beam-to-column joints, four half-scale internal joints with steel beams, and concrete filled tubing columns (CFT), and the results are as follows, displacement was tested under control load cycle. Square steel and tube column circles were considered with two different types of communication. Welded products, flat and curved extend of the end of the screw plates to the CFT column with steel bars passing through the column and through the type of connection's beam, in which the rays pass through the joint and are attached with additional screw brackets without the use of any weld between beam and column. According to the results of experiment, all subassemblies are applied in a flexible manner to large displacements with no apparent signs of local distress on the tube wall. The bars passing column were effective in both cases. Both circular and rectangular plate end connections showed similar performance [6].

Ling long et al. (2016) investigated the theory in local buckling of rectangular CFT column under abnormal pressure and according to their results, this formula is used to investigate the local buckling behavior of steel plates in an unconventional manner for a rectangular CFT column. They concluded that the local buckling pressure of the steel sheets on the rectangular CFT column was significantly affected by the stress coefficients and the width-to-thickness ratio while the cross-sectional dimension ratio (D / B) was slightly affected. As a final point, a suitable range was suggested for width / thickness ratio (B / T) and depth / thickness ratio (D / t ) at different stress ratios related to different ratios of cross-sectional aspects for steel plates in a rectangular CFT column. Furthermore, a suitable relationship was proposed for the thickness of steel plates at different stress slope coefficients for the design of rectangular CFT columns under abnormal pressure [7].

Yujie Yu et al. (2015) during a study investigated the effect of flange flexibility in WF-beam to rectangular CFT column connections. According to the results, both the Poisson effect and the flexibility of the column flanges lead to a change in the force flow pattern in the beam-to-column region and an inefficient moment of ability to transmit the beam through the web, as a result, high levels of demand for hydrostatic stress beam flanges are observed. Welding access holes, column flange thickness and diaphragm and connecting to website, all have a 
particular effect on the column flange, stiffness and transfer efficiency of the beam website. A flexural strength evaluation method is proposed for connecting rectangular CFT columns based on off-plane deformation [8].

Hassanein and Kharoob (2013) during a study concluded that the results of the available experiments do not cover all the ranges of diameter to thickness ratio of concrete-filled tube (CFT) columns. Therefore, in order to compensate for the scarcity of available results, they used the finite element method to perform numerical nonlinear simulations and investigated different $\mathrm{D} /$ te values of 47, 150 and more than 150 [9].

Ying et al (2014) during a study investigated hysteresis behaviors of crushed columns made of square (CFST) with connecting rods. In total, experiments were performed on ten square CFT columns consisting of eight specimens with connecting rods and two specimens without connecting rods under constant axial load and cyclic lateral loads. According to their results, the specimens with connecting rods show higher lateral bearing capacity, higher strength, higher ultimate deformation capacity and better energy dissipation capacity compared to the specimens without connecting rods.

Furthermore, local buckling is significantly delayed for specimens with connecting rods delayed by the connecting rods. In addition, the distance of the connecting rods has significantly improved lateral bearing capacity, ultimate deformation capacity, energy dissipation capacity and hardness of the specimens with the connecting rods. The ultimate deformation capacity decreases as axial load level increases while the energy dissipation capacity increases as axial load level increases [10]. Bridge and Oshea (2000) during a study found that an increase in the deviation from the center of force improves the ductility of the short columns. In concrete-filled (CFT) columns, the important effect of concrete is that it delays local buckling the steel wall, and the concrete itself in the nonconfined state is able to withstand higher strains and stresses than the non-confined state. The double-layered composite columns have more advantages then single-layered composite columns, such as the lower weight of the two-layered composite columns, greater ductility and greater axial load tolerance. What happens for a reinforced concrete member in most practical problem is simultaneous existence of axial load and bending anchor. In reinforced concrete frames with in-situ concrete pouring, even if the sides' openings of the column, bending anchors will be created in the column due to live load changes. Even with the use of prefabricated columns, horizontal loads caused by the beams falling and rising cause anchors in the column. Even if the sides' openings of a column are equal, flexural moment will be created in the column due to live load changes. Even if the prefabricated columns are used, horizontal loads caused by the beams rough-and-tumble leads to create moment in the column. According to mentioned earlier, it is necessary to apply a flexural moment according to the bylaws, even in the case of pure axial load theory applies to a reinforced concrete column, in order to make a minimum eccentricity along the axial load [11]. Talebi et al. (2018) during a study investigated a nonlinear threedimensional finite-element (FE) model to investigate the response of concrete-filled (CFTs) columns exposed to post-earthquake fires. Three stages were considered sequentially in the modeling, that is, cyclic, thermal and structural analyzes were performed. Three possible seismic damage scenarios in the column were considered. Damage levels are assumed as high damage levels, it is assumed that this column has reached $50 \%$ of its lateral resistance while still maintains its overall stability after the earthquake, while still maintaining overall postearthquake stability, has reached $50 \%$ of its lateral resistance. According to the results, the damages of the upper region didn't have any significant effects on the fire response of the damaged column. In addition, the column performs less fire resistance time with damage to the middle opening due to the location of the damage [12]. Hanifehzadeh and Mousavi (2019) simulated the response of the SCS wall exposed to explosion load near field. The structural performance of a typical SCS panel exposed to the blast load near the field is evaluated in terms of maximum damage and deformation. They investigated maximum deformation, plastic strain and failure state in different loading scenarios. They conducted a study aimed to predict the structural reaction of the SCS panel with different blast load and to identify the optimal configuration in terms of concrete strength and plate thickness. An optimization method was used to determine optimal parameters for each structural component. They concluded that the use of the proposed wall configuration will have better performance than conventional walls, while there is little extra cost to make it. [13]. Yang et al. (2019) during a case study collected the results of 491 concrete filled steel tube (CFT) column test results under axial load from existing literature. The results were used to investigate the effect of loading conditions, diameter to thickness ratio, concrete type and compressive strength on the loading capacity of CFT columns, which the models were used for the stress of steel pipe loops through nonlinear regression. A model has been developed to predict the load carrying capacity of CFT columns according to the Von Mises performance criterion analysis along with the proposed loop stress models. The performance of the proposed model and the existing models were investigated using a database. Given the rationality of the model development process, The proposed model makes possible to predict the bearing capacity of the CFT columns under different loading conditions in a more reasonable and accurate way [14]. Shariati et al. (2020) during a study investigated the behavior of concrete filled steel tube (CFT) column under axial pressure concrete numerically. They developed a finite element (FE) model to simulate the behavior of CFT columns. According to the results of comparison of the FE results and the test, the numerical model transmits the desired conditions and can predict the axial performance of the CFT column in an accurate way. Also, the load bearing capacity of the columns has 
been increased due to the greater effect on the blockade as steel pipe thickness increases. Also, the strength of concrete increases by increasing cross section area which leads to increase load bearing capacity compared with increasing steel pipe thickness. In CFT columns with more cross sections, the concrete strength is higher than the load-bearing capacity, which is significant in columns with weld lines [15]. According to the results reported by past studies, it can be concluded that the load bearing capacity of single-storey frame with concrete filled steel tube (CFT) column has not been investigated and further studies are needed.

\section{Research Method}

The finite element analysis of the CFT frame makes possible understanding real behavior at the lowest cost in the shortest time. The laboratory-based model is used for modeling as shown in Fig. 1.

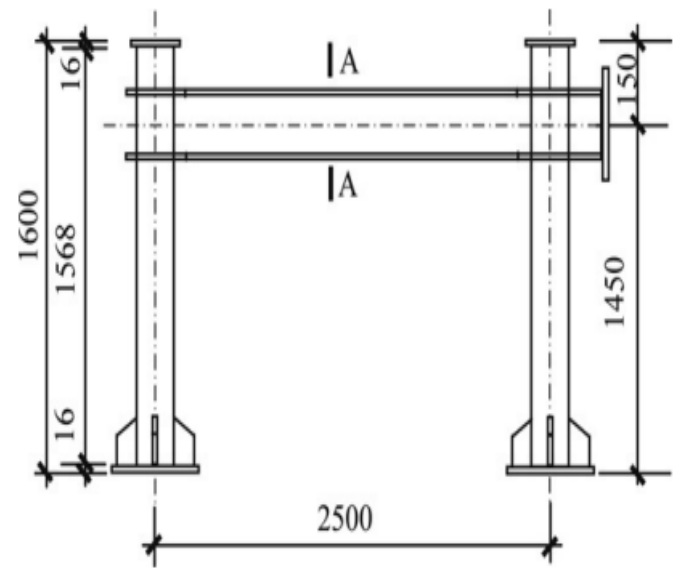

(a) Frame elevation.

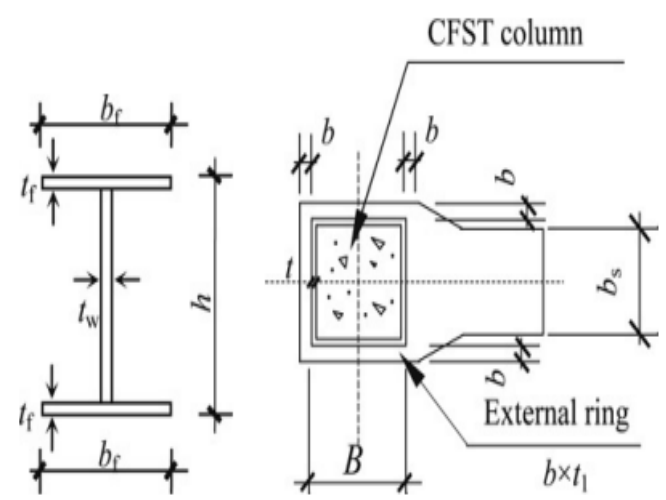

$\begin{array}{ll}\text { (b) A-A. } & \text { (c) Fabrication of joints. }\end{array}$

Figure 1- Dimensions and details of the laboratory-based model

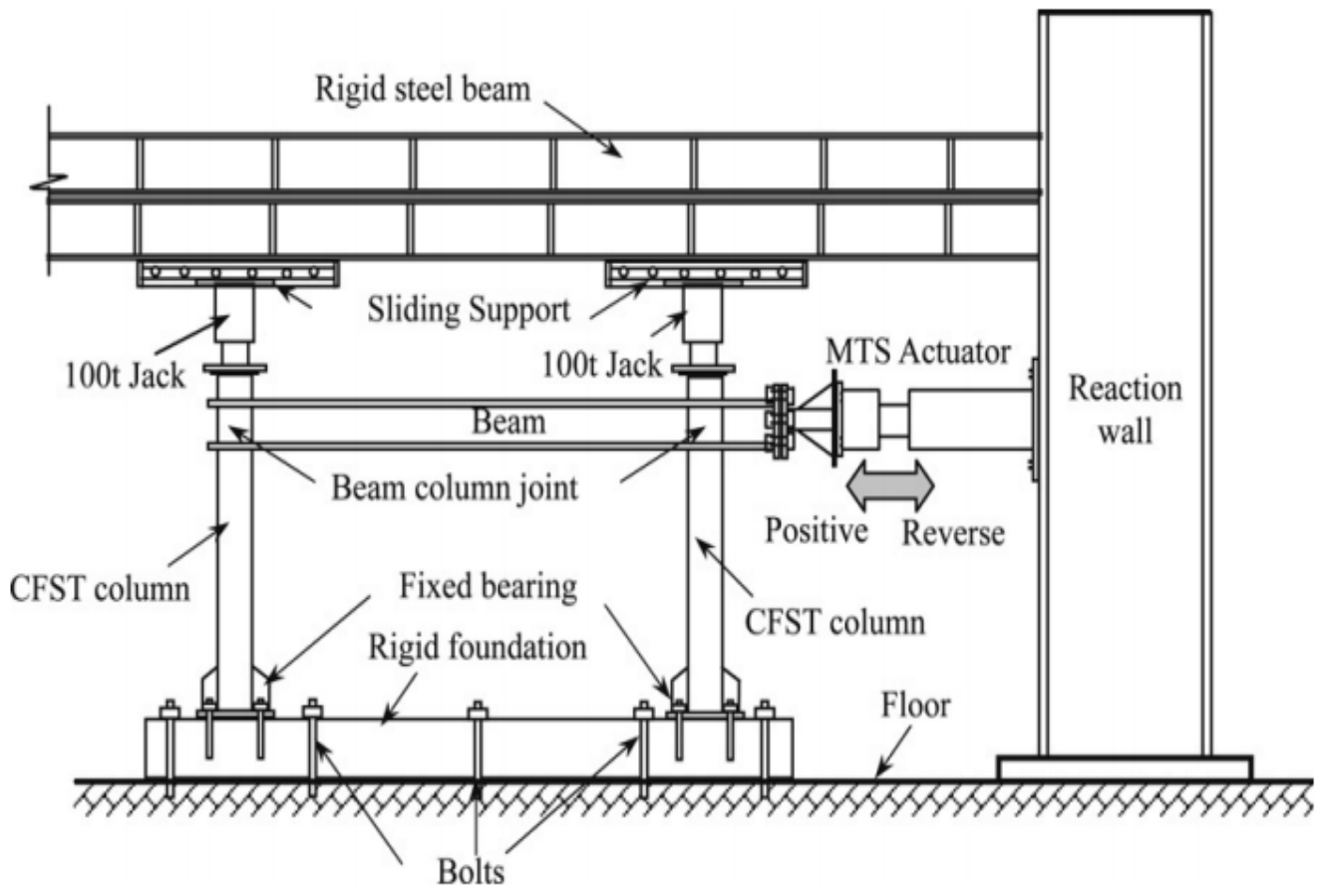

Figure 2- Laboratory model conditions 


\section{1- Modeling method}

The concrete core shell element was used for the steel column, which was reduced by the integral equation and modeled by brick (solid) element with three degrees of freedom of C3D8R for volume model and S4R for shell model. It should be noted that in the Reduced Integration elements there is less integration point in each direction than the full integration type. So, this difference can lead to the phenomenon called hour glass, which is due to the high flexibility of such elements. Therefore, elements must be small enough to be selected in the case of using Integration Reduced Linear Elements. Linear Reduced Integration is very resistant to distortion, so the use of this element with a small extrusion is recommended in models with a high degree distortion. The loading is applied uniformly on the upper plate so that the load is the same and in the opposite direction. A displacement type load corresponding to the desired rotation is considered. The upper and lower plates are attached to the desired column by the Tie command.

\section{2- Elements used in concrete and steel modeling}

Volumetric element is used to develop a concrete and shell element model for modeling steel around concrete and beams.

\section{3- Introducing Materials}

Materials are modeled in software nonlinearly. The nonlinear behavior with plasticity behavior of steel is considered for steel. Concrete Damage Plasticity damage model behavior is considered for concrete plasticity model.

\section{4- Frame assembly}

As shown in the figure, the components assembled and the orientation of each member were determined according to the sample geometry. Figure (3) shows the assembled sample.

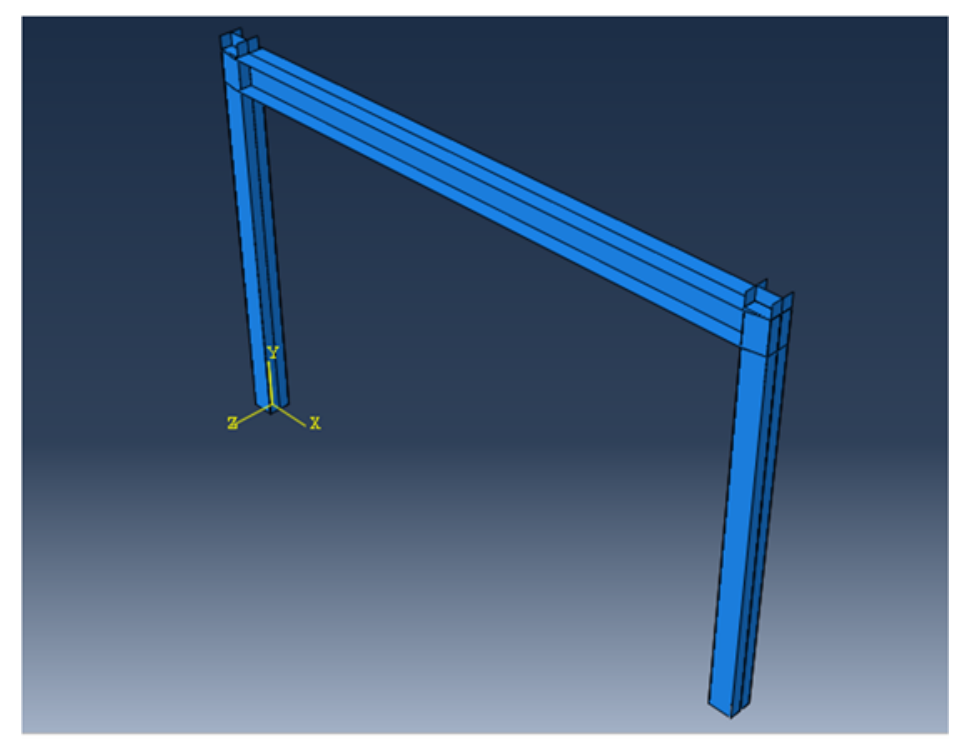

Figure (3) - Examined frame with concrete -filled tube column

\section{5- Type of analysis}

Dynamic step-by-step sequence analysis can solve the problems with high structural deformation. Implicit dynamic analysis is used. Dynamic implicit analysis is used.

\section{6- Interaction between steel and concrete}

The interaction between steel and concrete is an important issue that needs further attention and investigation. The contact algorithm was used to define the contact between steel and concrete. Hard contact behavior and penalty algorithm were used.

\section{7- Boundary and loading conditions}

The supporting conditions for the model are determined. The model of a concrete-filled tube column with supporting conditions are shown in figure 4. The simulation of laboratory conditions of the specimen are performed under ram force. For this purpose, displacement protocol according to SAC loading protocol is performed on the specimen at the top of the. But for earthquakes, the earthquake displacement is applied to the columns' support. 


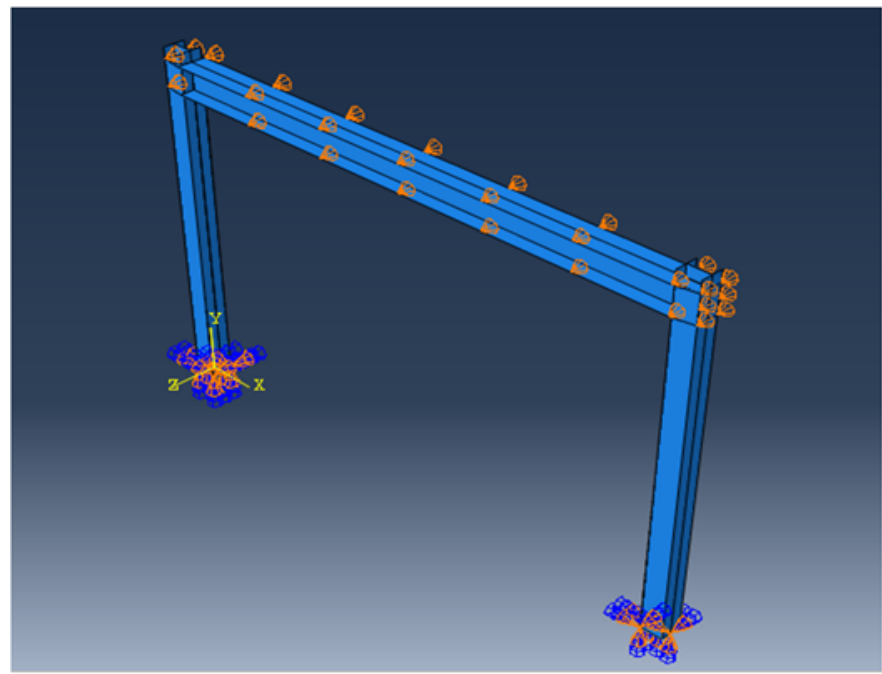

Figure (4) Model with support conditions

The load is applied to the structure as drift control. The sac loading protocol is used.

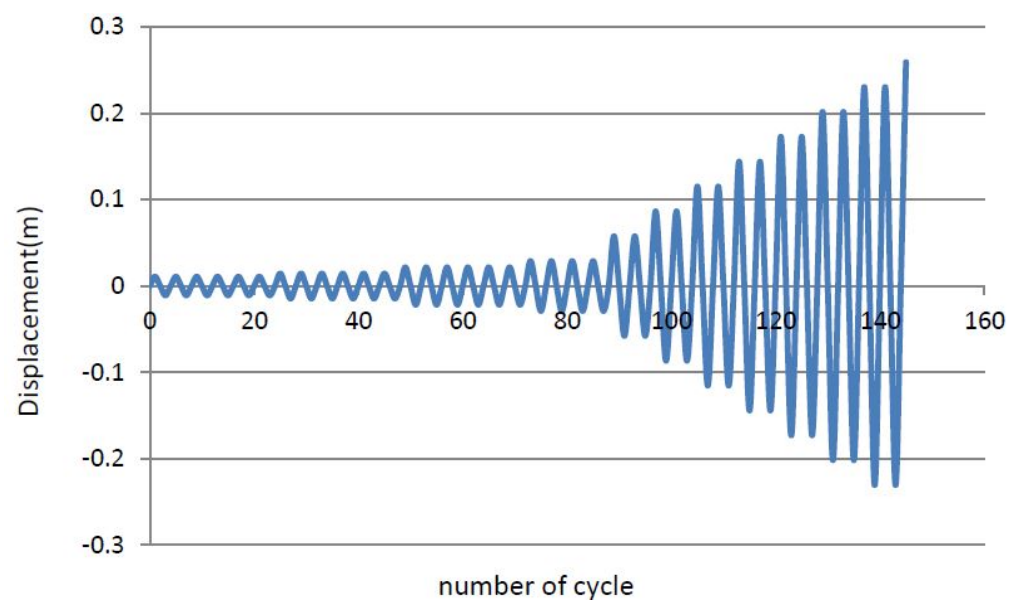

Figure (5) cyclic loading pattern

\section{8- Meshing}

Meshing algorithms are used for the meshing of concrete and steel. The mesh should be precise and the nodes and investigation of meshing should be carried out in terms of dimensions and accuracy as well as the volume of computations and outputs in an optimal way. The optimal final meshing is shown in figure 6.

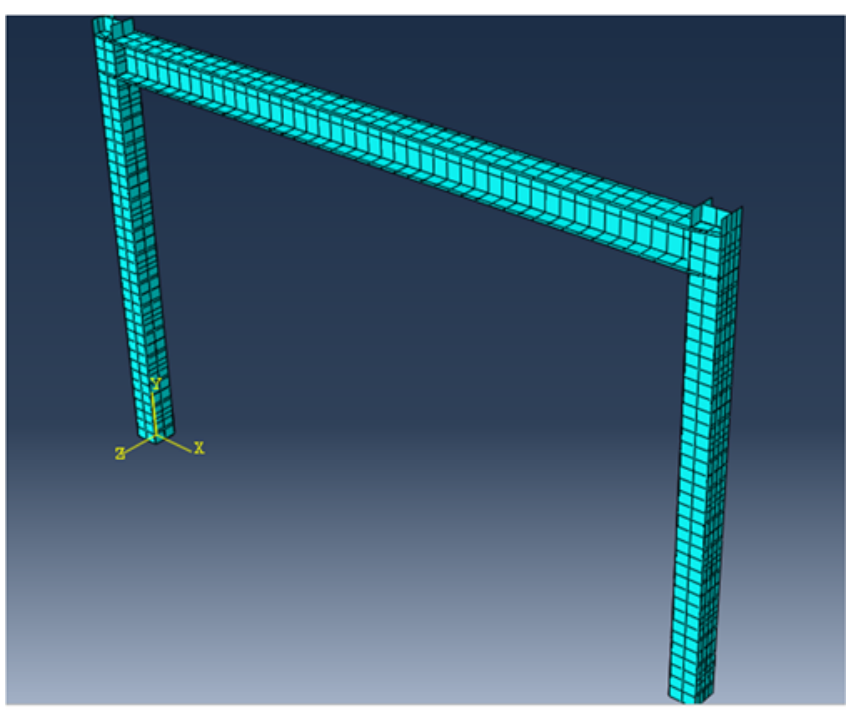

Figure (6) Meshing of the model 


\section{Research results}

Different examples are examined in this section. The 1, 2 and 3-story steel moment frames are compared with the concrete-filled tube column frame. The displacement controlled cyclic loading was done and the results have been compared for the frames studied. Then, the studied specimens were subjected to a number of actual earthquakes, and time displacement, deformation and hysteresis displacement diagrams of the specimens were compared. The results are as follows.

\section{1- Investigation of frames under earthquake}

The following figures show the behavior of 1, 2 and 3-story frames under different earthquakes in two states with and without concrete filled columns.

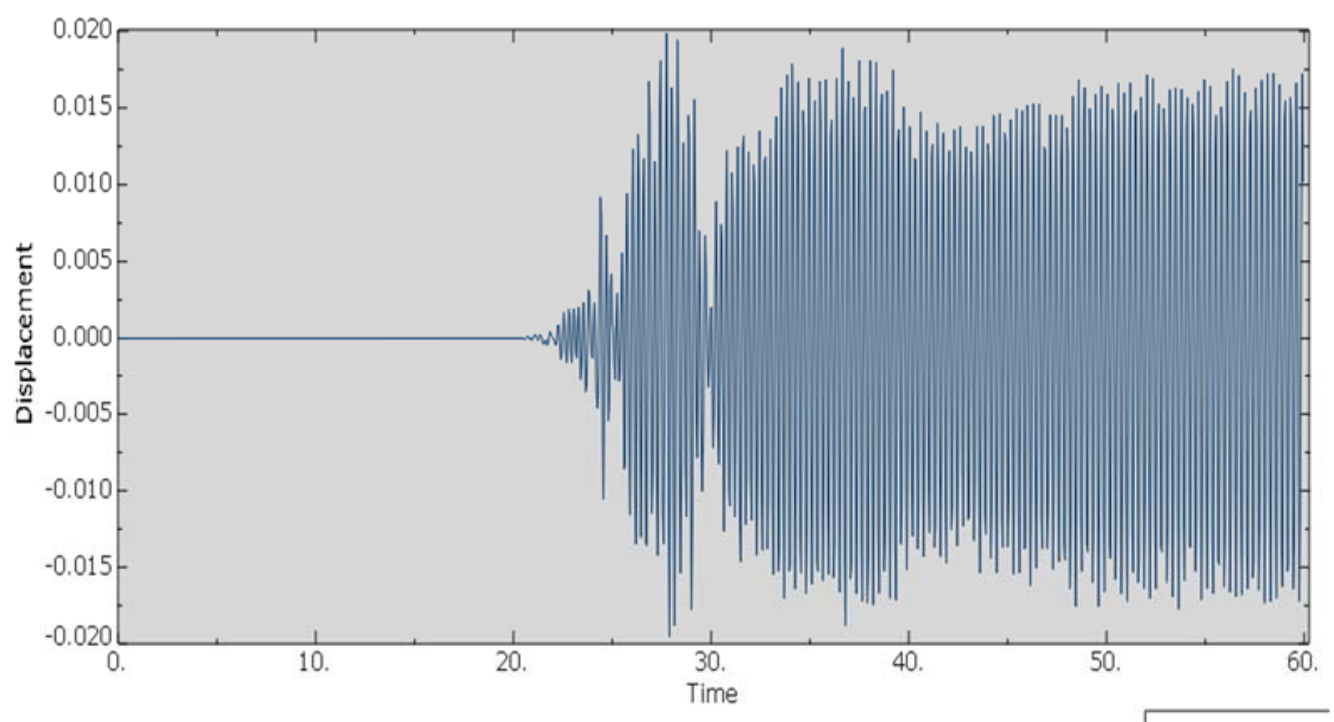

Figure (7) History of the amount of displacement of a 1-story concrete-steel frame for the Chalfant Valley earthquake

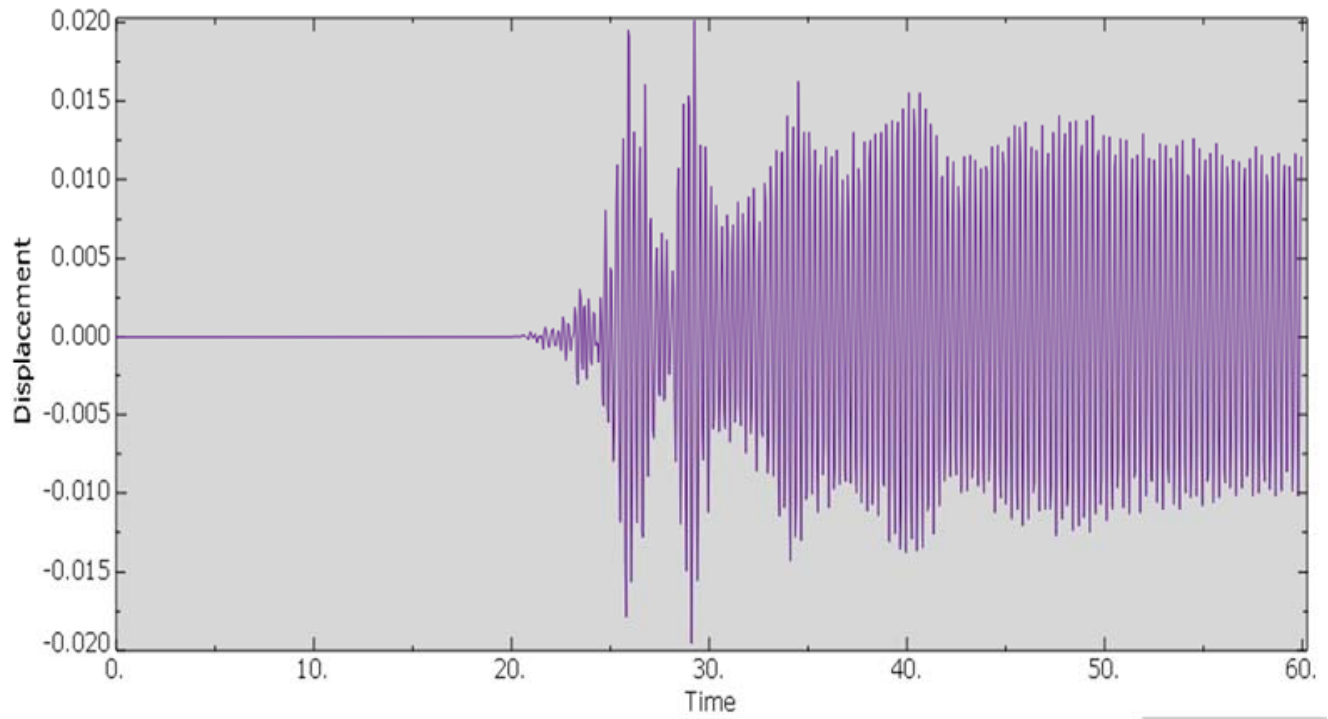

Figure (8) History of the amount of displacement of a 1-story concrete-filled steel frame for the Chalfant Valley earthquake

History of structure displacement is investigated for the duration of the earthquake, about 60 seconds for the time when the earthquake acceleration affects the structure. The moment frame displacement of a 1-story steel moment frame for the Chalfant Valley earthquake was $2 \mathrm{~cm}$ in maximum. The maximum displacement value of the moment frame of a 1-story concrete-filled steel moment frame was obtained about $1.9 \mathrm{~cm}$. 


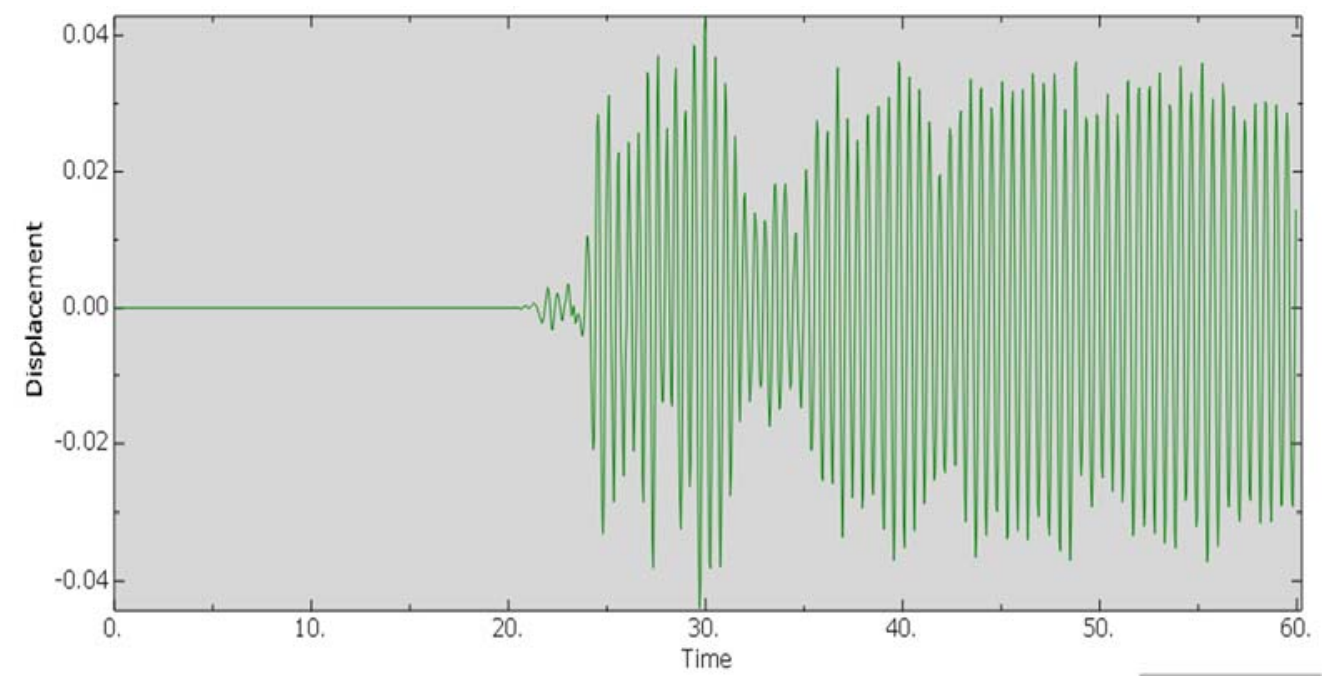

Figure (9) History of the amount of displacement of the 2-story steel frame for the Chalfant Valley earthquake

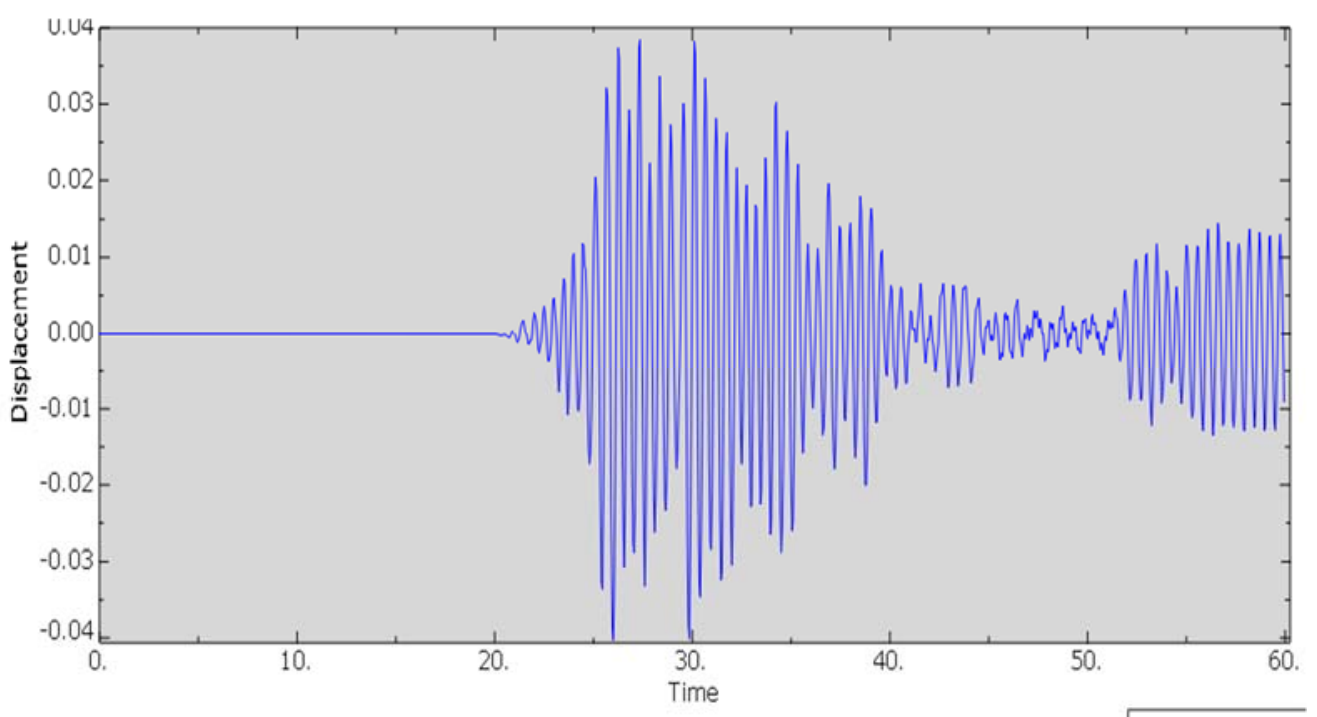

Figure (10) History of the amount of displacement of 2-story concrete -filled steel frame for Chalfant Valley earthquake

The moment frame displacement of a 2-story steel moment frame for the Chalfant Valley earthquake was $4.2 \mathrm{~cm}$ in maximum. The maximum displacement value of the 2-story concrete-filled steel moment frame was obtained about $4 \mathrm{~cm}$.

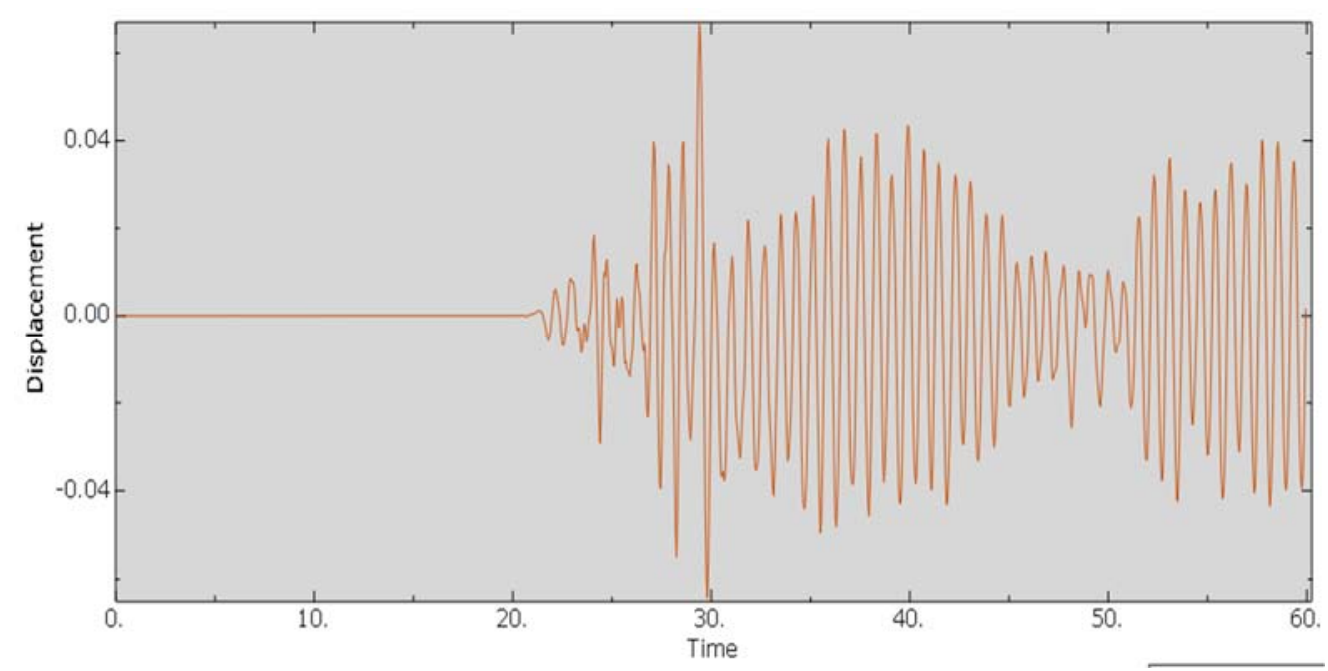

Figure (11) History of the amount of displacement of the 3-story steel frame for the Chalfant Valley earthquake 


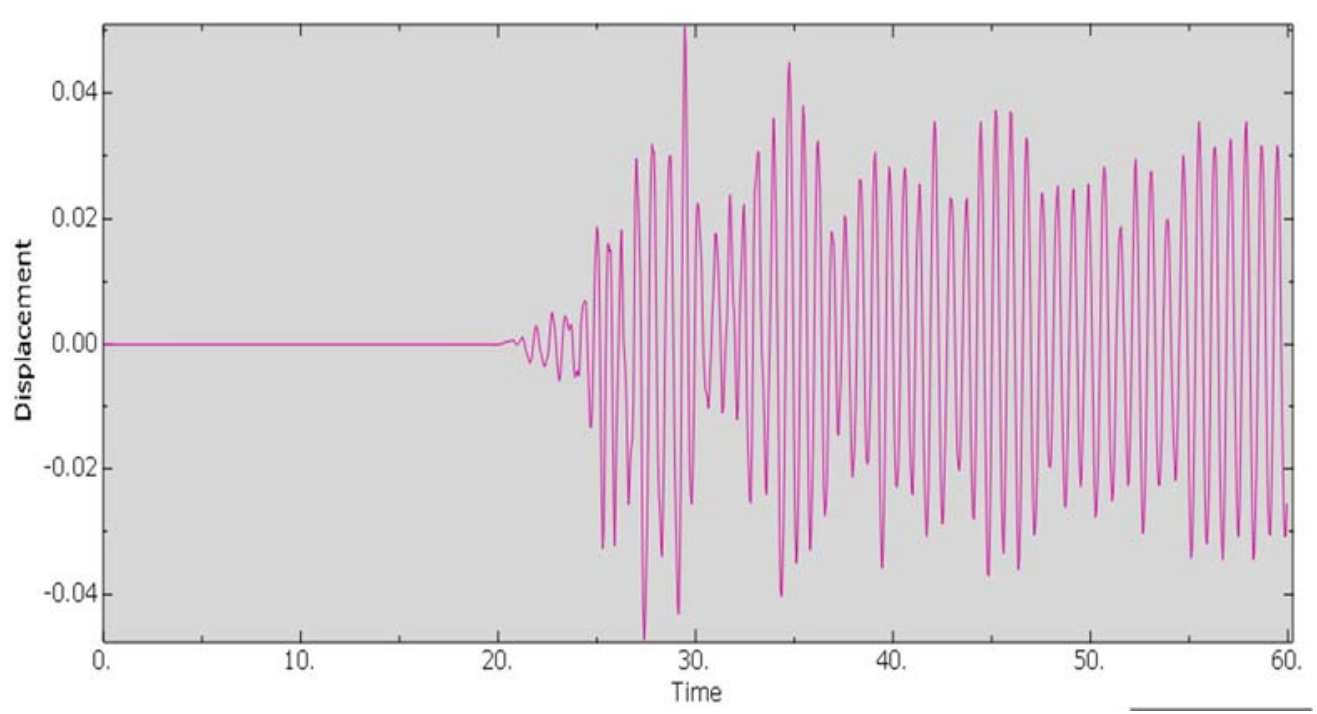

Figure (12) History of the amount of displacement of 3-story concrete -filled steel frame for Chalfant Valley earthquake

The moment frame displacement of a 3-story steel moment frame for the Chalfant Valley earthquake was $5.5 \mathrm{~cm}$ in maximum. The maximum displacement value of the 3-story concrete-filled steel moment frame was obtained about $5 \mathrm{~cm}$.

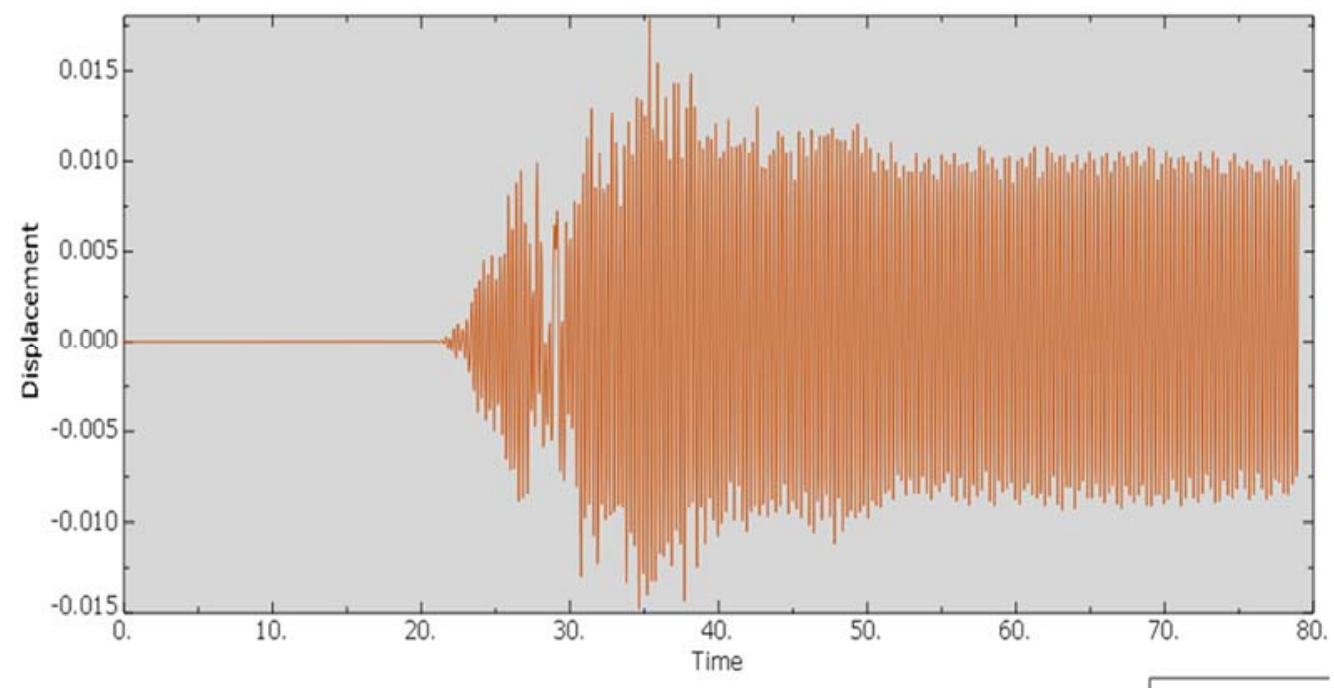

Figure (13) History of the amount of displacement of a 1-story concrete-steel frame for the Coalinga earthquake

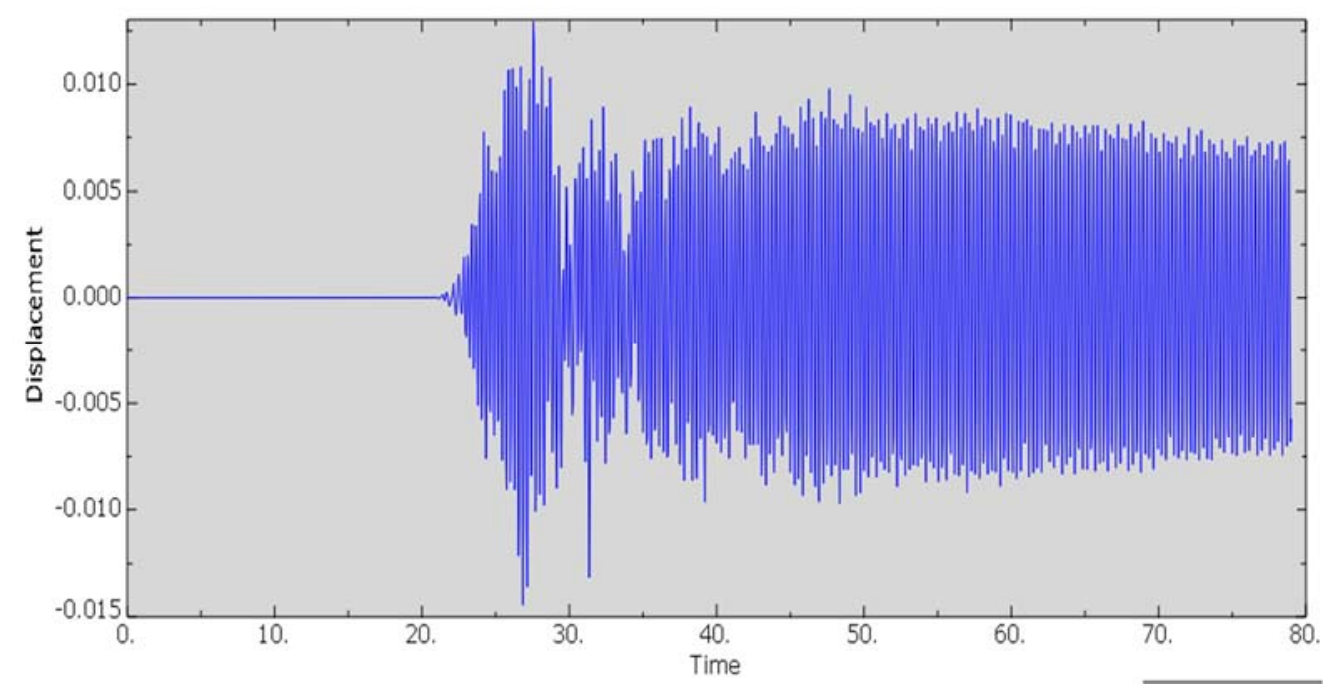

Figure (14) History of the amount of displacement of a 1-story concrete-filled steel frame for the Coalinga earthquake 
History of structure displacement is investigated for the duration of the earthquake, about 60 seconds, for the time when the earthquake acceleration affects the structure. The moment frame displacement of a 1-story steel moment frame for the Coalinga earthquake was $1.7 \mathrm{~cm}$ in maximum. The maximum displacement value of the moment frame of a 1-story concrete-filled steel moment frame was obtained about $1.2 \mathrm{~cm}$.

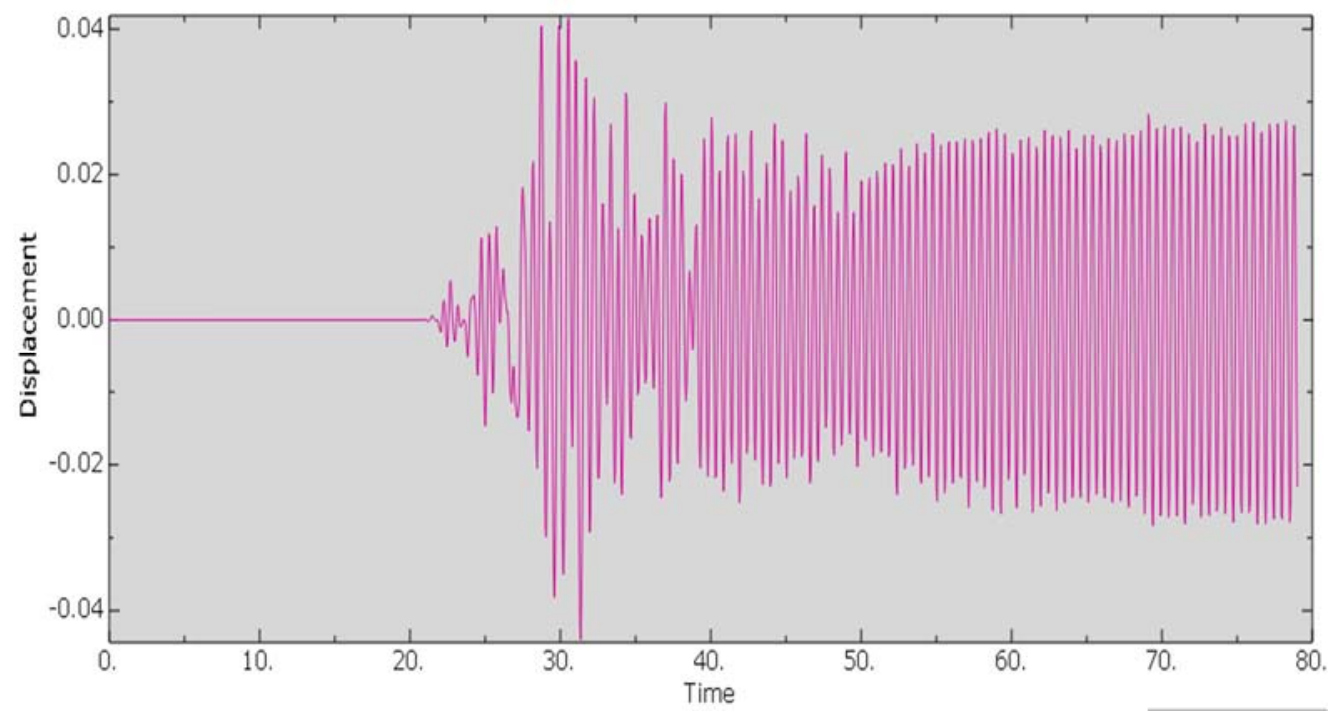

Figure (15) History of the amount of displacement of the 2-story steel frame for the Coalinga earthquake

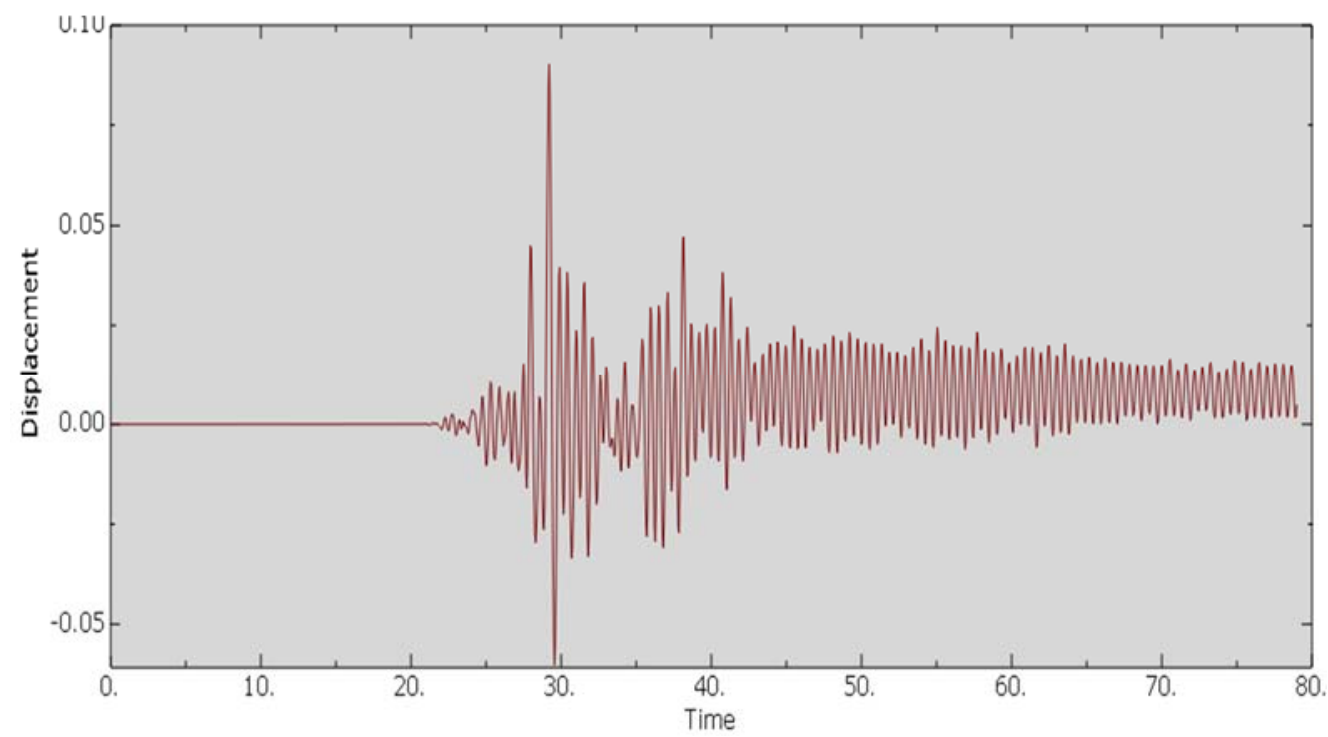

Figure (16) History of the amount of displacement of 2-story concrete -filled steel frame for Coalinga earthquake

The moment frame displacement of a 1-story steel moment frame for the Coalinga earthquake and in the $\mathrm{X}$ direction was $4.2 \mathrm{~cm}$ in maximum. The maximum displacement value of the 1-story concrete-filled steel moment frame was obtained about $1 \mathrm{~cm}$.

\section{Conclusion}

The present study has investigated the behavior of frames with and without concrete-filled tube columns. The results are summarized as follows:

1) According to the hysteresis behavior of the specimen, in the steel moment-frame with concrete-filled tube column, it increased the greater force tolerance of the ordinary steel moment-frame.

2) The concrete-filled tube column prevents the buckling of the concrete into the column and delays the local buckling of the steel wall.

3) The concrete-filled steel frame has a better energy dissipation than the steel frame.

4) The amount of displacement with different concrete-filled steel frames was lower than that of steel frame roof displacement, indicating the performance of frame has increased.

5) The presence of concrete in the steel column increases the bearing capacity of the column under the earthquake and cyclic load. 
6) The presence of concrete in the column has a significant effect on the behavior of the frame so that damage occurs in the concrete-filled column at the panel zone and the column has a good behavior, but occurs in the steel column under buckling earthquake.

7) The bearing capacity of the concrete-filled steel column increases due to interaction between concrete and steel.

\section{Reference:}

[1] Ketan Patel, And Sonal Thakkar, Analysis of CFT, RCC and Steel Building Subjected to Lateral Loading, Procedia Engineering,Volume 51, 2013, Pages 259-265

[2] Ankur Tailor, Dalal, And Desai, Comparative Performance Evaluation of Steel Column Building \& Concrete Filled Tube Column Building under Static and Dynamic Loading, Procedia Engineering 173 ( 2017 ) 1847 - 1853

[3] N. Jamaluddin, Lamb , And Dai, An experimental study on elliptical concrete filled columns under axial compression, Journal of Constructional Steel Research Volume 87, August 2013, Pages 6-16

[4] Mohamed Mahmoud El-Heweity, On the performance of circular concrete-filled high strength steel columns under axial loading, Alexandria Engineering Journal,Volume 51, Issue 2, June 2012, Pages 109-119

[5] M.H. Lai, And J.C.M. Ho, Uni-axial Compression Test of Concrete-filled-steel-tube Columns Confined by Tie Bars, Procedia Engineering,Volume 57, 2013, Pages 662-669

[6] Gunasekaran, Sheet, And MacRae, Experimental investigation of CFT column to steel beam connections under cyclic loading, Journal of Constructional Steel Research, Volume 86, 2013, Pages 167-182

[7] Ling Long, Jun Wan, AndJian Cai, Theoretical study on local buckling of rectangular CFT columns under eccentric compression, Journal of Constructional Steel Research, Volume 120, 2016, Pages 70-80

[8] Yujie Yu,60- Chen,And Wang, Effect of column flange flexibility on WF-beam to rectangular CFT column connections, Journal of Constructional Steel Research Volume 106, March 2015, Pages 184-19.

[9] M.F. Hassanein , O.F. Kharoob . " Compressive strength of circular concrete-filled double skin tubular short columns ".Thin-Walled Structures (2013), http://dx.doi.org/10.1016/j.tws.2013.10.004i

[10] Wang, Ying-Tao, Jian Cai, and Yue-Ling Long. "Hysteretic behavior of square CFT columns with binding bars." Journal of Constructional Steel Research 131 (2017): 162-175.

[11] By Martin D. O'Shea,1 Member, ASCE, and Russell Q. Bridge,2 Fellow, ASCE. "DESIGN OF CIRCULAR THIN-WALLED CONCRETE FILLED STEEL TUBES" JOURNAL OF STRUCTURAL ENGINEERING / NOVEMBER 2000.126:1295-1303.

[12] Talebi, Elnaz, Manfred Korzen, and Sascha Hothan. "The performance of concrete filled steel tube columns under post-earthquake fires." Journal of Constructional Steel Research 150 (2018): 115-128.

[13] Hanifehzadeh, Mohammad, and Mir Mohammad Reza Mousavi. "PREDICTING THE STRUCTURAL PERFORMANCE OF SANDWICH CONCRETE PANELS SUBJECTED TO BLAST LOAD CONSIDERING DYNAMIC INCREASE FACTOR." Journal of Civil Engineering, Science and Technology 10, no. 1 (2019): 45-58.

[14] Wei, Yang, Cheng Jiang, and Yu-Fei Wu. "Confinement effectiveness of circular concrete-filled steel tubular columns under axial compression." Journal of Constructional Steel Research 158 (2019): 15-27.

[15] Shariati, Mahdi, Morteza Naghipour, Ghazaleh Yousofizinsaz, Ali Toghroli, and Nima Pahlavannejad Tabarestani. "Numerical study on the axial compressive behavior of built-up CFT columns considering different welding lines." Steel and Composite Structures 34 , no. 3 (2020): 377. 